\title{
La inmigración y la crisis. Los polacos en el Buenos Aires de la década de los años treinta*
}

The Immigration and the Crisis. The Poles in the Buenos Aires of the 1930s

\author{
Katarzyna Porada \\ ORCID iD: http://orcid.org/0000-0002-6161-2065 \\ CONICET, Argentina
}

El presente artículo se centra en la inmigración polaca radicada en la ciudad de Buenos Aires en la primera mitad de la década de los años treinta del siglo XX. Se estudiará aquí el impacto que la crisis económica mundial desatada en 1929 tuvo sobre este grupo particular y se analizarán las medidas tomadas por la colectividad para atenuar sus secuelas. Al mismo tiempo, se indagará sobre el porqué de la alta vulnerabilidad de los inmigrantes polacos en el contexto argentino.

Palabras clave: Crisis Económica; Periodo de Entreguerras; Buenos Aires; Inmigración Polaca en Argentina.

This paper focuses on Polish immigration in Buenos Aires in the first half of the $30 \mathrm{~s}$ of the 20th century. It analyzes the impact that the world economic crisis unleashed in 1929 had on this particular group and studies the measures taken by the community to mitigate its consequences. At the same time, it inquires about the reason for the high vulnerability of the Polish immigrants in the Argentine context.

Keywords: Economic Crisis; The Interwar Period; Buenos Aires; Polish Immigration in Argentina.

Copyright: (C) 2019 CSIC. Este es un artículo de acceso abierto distribuido bajo los términos de la licencia de uso y distribución Creative Commons Reconocimiento 4.0 Internacional (CC BY 4.0).

* Este artículo se inserta en el marco del proyecto de investigación HAR2015-63689-R, financiado por el Plan Nacional de I+D+i del Ministerio de Economía y Competitividad de España. 
Tras el estancamiento económico provocado por la Primera Guerra Mundial, en la década de 1920 Argentina experimentó un importante crecimiento económico. Al igual que en el periodo de preguerra, el país volvió a ocupar el primer puesto a nivel mundial en las exportaciones de los productos agrarios, principalmente carne refrigerada, maíz, lino y cereales. En forma gradual y sostenida creció también el sector de la industria. El desarrollo de las actividades industriales y agropecuarias promovió, a su vez, la construcción de caminos, ferrocarriles y puertos. Se produjo un aumento moderado de los salarios reales de los trabajadores, que en 1921 superaron los niveles del comienzo de la guerra y alcanzaron su punto máximo en 1928. ${ }^{1}$ Con todo ello, hacia finales de los años veinte, Argentina se ganó la reputación mundial de un país al que le esperaba un futuro próspero y que iba a representar un papel importante en la economía mundial. ${ }^{2}$ Seguidamente, la necesidad de la mano de obra propició el restablecimiento de la inmigración interrumpida con el estallido del conflicto bélico. A diferencia de las épocas anteriores, en el periodo de entreguerras se registró un cambio en la composición de los movimientos migratorios. Si bien los italianos y los españoles seguían siendo la mayoría de los arribados al puerto de Buenos Aires, se observó una importante expansión de los inmigrantes centroeuropeos. Dentro de este grupo, los polacos llegaron a constituir un $12 \%$ del total de los ingresados al país.

La relativa bonanza económica de los años veinte quedó interrumpida por el estallido de la crisis económica mundial de 1929. Su consecuencia más inmediata fue el aumento de la desocupación, fenómeno que afectó tanto a los trabajadores nacionales como a los extranjeros. En el presente artículo nos proponemos analizar la situación de los inmigrantes polacos radicados en la ciudad de Buenos Aires al inicio de los años treinta. En primer lugar, esbozaremos las características de los movimientos migratorios entre ambos países y el perfil de los trabajadores polacos establecidos en la capital argentina en este periodo. Posteriormente, nos proponemos estudiar el impacto que la crisis económica mundial tuvo sobre este grupo particular. Analizaremos también las medidas que fueron tomadas por la colectividad polaca para atenuar las secuelas de la crisis entre los connacionales más afectados. Por último, pretendemos indagar sobre el porqué de la alta vulnerabilidad de los polacos en el contexto argentino.

1 González Leandri, 2001, 209.

2 Palacio, 2000, 142. 


\section{Polonia y los movimientos migratorios}

Los inicios de la migración polaca a gran escala con destino a Argentina datan de la última década del siglo XIX y corresponden a una Polonia dividida entre grandes potencias vecinas: Rusia, Imperio Austrohúngaro y Prusia. Desde entonces y hasta el estallido de la I Guerra Mundial, rumbo a Argentina emigraron aproximadamente treinta y dos mil personas, de las que unas diez mil se dirigieron hacia la provincia de Misiones. ${ }^{3}$ Los arribados en este periodo provenían mayoritariamente de la parte anexada al Imperio Austrohúngaro y, en mucho menor grado, de Rusia. El año 1918, además de poner fin al conflicto bélico, significó para Polonia la recuperación de la independencia. Tras el júbilo inicial generalizado, resultó evidente que el país sufría de una gran inestabilidad política, económica y social; problemas a los que pronto se sumaron los conflictos armados originados en 1919 por la delimitación de la frontera oriental. ${ }^{4}$ Debido a los importantes cambios geopolíticos, una vez lograda la independencia, Polonia se convirtió en un país multinacional en el que los polacos, según el censo nacional de 1931, conformaban un 68,9 \% de la población. Entre las minorías más numerosas, los ucranianos constituían un 10,1\% (un 13,1\% de la población del campo) y los judíos un 8,6 \% (un 24,3 \% de la población residente en las ciudades). ${ }^{5}$

La conflictividad interna fue, además, acompañada por una alta tasa de desocupación, la caída de salarios y la consecuente precarización de las condiciones de vida y trabajo. Esta situación se agudizó en 1921 tras la desmovilización de una parte sustancial del ejército polaco. ${ }^{6}$ Según las estadísticas oficiales, en 1928, en un país con una población de aproximadamente treinta millones de habitantes, el número de personas catalogadas como «sobrantes» — es decir, aquellas que no tenían las posibilidades de ser absorbidas por el mercado laboral — alcanzaba tres millones. En 1933 esta cifra ascendió hasta cuatro millones y medio. ${ }^{7}$ Se trataba mayoritariamente de personas pertenecientes al sector agrario. En este contexto, las autoridades polacas comenzaron a poner mayor interés en el fenómeno de la emigración, percibida como una manera viable de solucionar el problema

3 Mazurek, 2006, 90.

4 Janowska, 1984, 421.

5 Maty Rocznik Statystyczny, 1939, 23.

6 Mazurek, 2006, 91.

7 Mazurek, 2011, 45. 
de la desocupación y aliviar las tensiones internas del país. ${ }^{8}$ Desde la década del veinte, con el apoyo oficial, en todo el territorio nacional empezaron a fundarse las oficinas emigratorias destinadas a brindar apoyo a los futuros emigrantes e informar sobre las posibilidades laborales en los países de destino. ${ }^{9}$ Se instauró también una red de hoteles que albergaban y ofrecían manutención a los futuros emigrantes antes de emprender el viaje. En la misma época, se inició la construcción de la ciudad portuaria de Gdynia. Primero se estableció la conexión entre la ciudad polaca y los puertos europeos que ofrecían la conexión directa con los puertos latinoamericanos y, desde la década del treinta, se inauguraron las primeras trayectorias transoceánicas. ${ }^{10}$ La construcción del puerto polaco acortó el viaje y redujo considerablemente los gastos.

En comparación con el periodo anterior a la I Guerra Mundial, en la época de entreguerras la emigración polaca hacia Argentina aumentó considerablemente. Si bien las políticas proemigratorias pueden haber influido en la promoción de este destino latinoamericano, un factor de esencial importancia para su gran crecimiento cuantitativo fue la introducción de nuevas restricciones en la política inmigratoria de los Estados Unidos. Hasta las primeras décadas del siglo XX, este país norteamericano era el principal receptor de los movimientos migratorios transoceánicos originados en las tierras polacas. En el periodo 1871-1913 los Estados Unidos recibieron 1,9 millones de personas de este origen. ${ }^{11}$ No obstante, la Ley de Origenes Nacionales promulgada en 1924, popularmente conocida como la ley de cuotas, limitó la inmigración de los ciudadanos polacos hasta seis mil ingresos anuales. ${ }^{12}$ Consecuentemente, a partir de la segunda mitad de los años veinte tuvo lugar una considerable reorientación de los destinos migratorios polacos, convirtiéndose Argentina en un destinto atrayente y relativamente accesible. En las dos décadas que separan las guerras mundiales, a Argentina inmigraron 160.000 ciudadanos polacos; dentro del conjunto de los emigrados, la tercera parte la constituyeron los judeo-polacos. ${ }^{13}$ El mayor crecimiento migratorio fue registrado entre 1926 y 1930; en este periodo de apenas cinco años al puerto de Buenos Aires arribaron aproximadamente 95.000 personas. Es decir, en el lustro anterior a la crisis económica

\footnotetext{
8 Porada, 2016, 135.

9 Nalewajko, 2014, 139-145.

10 Smolana, 1983, 45.

11 Mazurek, 2006, 30.

12 Brożek, 1984, 132-133.

13 Mazurek, 2006, 91-92.
} 
mundial llegaron a Argentina más ciudadanos polacos de los que habían llegado desde que se iniciaron los movimientos migratorios entre ambos países. Al mismo tiempo, las tasas de retorno eran relativamente bajas. En los años 1922-1938 regresaron a Polonia dieciocho mil personas. ${ }^{14}$

Las secuelas de la crisis económica mundial se reflejaron en las restricciones en la legislación migratoria argentina. En este contexto, los sucesivos gobiernos optaron por proteger los intereses de los que residían en el país, obstaculizando la llegada de los trabajadores potenciales. En un primer momento, se pretendió frenar los ingresos al país elevando las tasas consulares. La imposición de los obstáculos administrativos no desalentó sustancialmente la inmigración, por lo que, en noviembre de 1932, el año más crítico de la depresión, se promulgó el decreto que expresaba lo siguiente:

en defensa de los trabajadores radicados en la Argentina no sería prudente en las actuales circunstancias autorizar la entrada al país de quienes no tengan de antemano asegurada una ocupación remunerativa o la subsistencia. ${ }^{15}$

En los primeros años de la década del treinta, la inmigración europea hacia Argentina disminuyó de manera considerable: de 195.000 ingresos anuales en el año 1923 pasó a 24.300 en $1933 .{ }^{16}$ En el mismo periodo, los ingresos de los ciudadanos polacos no alcanzaron las dos mil personas. ${ }^{17}$ Este espectacular descenso, sin embargo, más que a las restricciones en las política migratorias, se debía principalmente a las condiciones económicas poco favorables y se inscribía dentro del panorama general de los movimientos migratorios transatlánticos.

\section{Los inmigrantes polacos en la Argentina de entreguerras}

Al igual que en las épocas anteriores, la inmigración polaca del periodo de entreguerras se caracterizó por ser mayoritariamente rural. ${ }^{18} \mathrm{El}$ $77,5 \%$ de las personas laboralmente activas que en los años 1926-1938 se

14 Matelski, 2016, 198.

15 Oteiza, 2000, 145.

16 Devoto, 2009, 363.

17 Smolana, 1983, 56.

18 Los datos disponibles referentes a las personas emigradas desde Polonia en el periodo anterior al año 1926, no contemplan la división entre personas laboralmente activas y pasivas, ni registran la profesión en el momento de emigrar, por lo que se trata de estimaciones orientativas. Después de 1926, si bien esas dos categorías aparecen en las estadísticas oficiales, no se incluye la correlación entre el sexo y la profesión. Tampoco aparece el estado civil de los emigrados, ni la edad en el momento en que se produjo la emigración. 
dirigieron hacia Argentina declararon desempeñar actividades ligadas a la agricultura. ${ }^{19}$ Bajo esta categoría quedaban registrados los pequeños propietarios, los campesinos sin tierra, los jornaleros y un pequeño porcentaje de artesanos rurales. Del resto de los emigrados, un 15,5\% eran trabajadores del sector de la industria (categoría que incluía obreros industriales calificados, obreros no calificados y artesanos urbanos), un 5,5\% eran empleados de servicio doméstico y, por último, un 1,5\% declaraban ser comerciantes. ${ }^{20}$ En el periodo analizado los movimientos migratorios polacos destacaron por su alto grado de masculinización. Si bien la superioridad numérica de hombres (220 por cada 100 mujeres) era un rasgo propio de todo el periodo de la inmigración de masas hacia Argentina, ${ }^{21}$ el caso polaco estaba muy por encima de la media. En 1926-1930 por cada 400 hombres de nacionalidad polaca ingresaban a Argentina 100 mujeres de este mismo origen. Cabe aclarar que en este panorama una importante excepción la constituyeron los ciudadanos polacos de origen judío. Dentro de este grupo, el índice de masculinidad era mucho menos pronunciado, manteniéndose al nivel de 150 hombres por 100 mujeres. ${ }^{22}$ A modo de comparación, en la misma época, en los disminuidos movimientos migratorios polacos hacia los Estados Unidos, las mujeres constituían un $55 \%$ del total de los emigrados. ${ }^{23}$

La alta masculinización para el caso argentino, excluyendo a los polacos judíos, ${ }^{24}$ demuestra una importante inestabilidad del proceso migratorio. ${ }^{25}$ La estrategia migratoria pudo haber consistido en emigrar primero el hombre, trabajar un determinado periodo hasta alcanzar cierta seguridad económica y, después, contemplaba la reagrupación familiar. Las fuentes étnicas demuestran, además, que entre los inmigrantes también hubo un porcentaje significativo de hombres que dejaron en el país a sus familiares económicamente dependientes y planeaban retornar después de dos o tres años, tras haber acumulado un cierto capital. ${ }^{26}$ En cualquier caso, muchos

\footnotetext{
19 Janowska, 1984, 413.

20 Ibidem, 415.

21 Devoto, 2007, 540.

22 Janowska, 1984, 437.

23 Ibidem, 435-437.

24 Kowalska, 1989, 257.

25 La relación entre la creciente feminización y la estabilidad de movimientos migratorios fue destacada también por Pilar Cagiao para el caso de la inmigración gallega (Cagiao Vila, 2007, 157).

26 La existencia de una fuerte expectativa de retorno quedó demostrada en las fuentes étnicas, principalmente en las cartas de lectores publicadas en la prensa étnica entre 1919-1939. Nos basamos en la muestra de 350 cartas, de ocho publicaciones de la colectividad polaca en Argentina (Stowo Polskie, Głos Polski, Or downik, Codzienny Niezale ny Kurier Polski, Osadnik, Przyjaciel Ludu, Pobudka,
} Gazeta Polska w Argentynie). 
de estos proyectos iniciales, fuesen a corto, mediano o largo plazo, quedaron postergados debido a la crisis económica mundial. Inclusive podemos aventurarnos a afirmar que una parte de los emigrados optaron por quedarse en Argentina por no cumplirse sus expectativas iniciales y por negarse a reconocer ante su entorno más cercano el fiasco de la experiencia migratoria.

Los datos referentes al lugar de establecimiento de los polacos arribados en el periodo de entreguerras señalan la existencia de patrones territoriales muy diversificados. Una parte se radicó en las comunidades polacas fundadas ya antes de la I Guerra Mundial o en sus proximidades. Este fue el caso de los polacos que se dirigieron a la provincia de Misiones, donde desde finales del siglo XIX se habían ido radicando agricultores polacos. Su establecimiento, primero, en Apóstoles, Azara, Corpus, Cerro Corá y, posteriormente, en Bonpland, Polana, Gobernador Roca y Colonia Wanda, entre otros, dio lugar al desarrollo de una compacta colectividad polaca en la región. ${ }^{27}$ Se calcula que en el periodo de entreguerras se dirigieron hacia el nordeste argentino aproximadamente cinco mil personas. ${ }^{28} \mathrm{La}$ actividad económica de los colonos se centró principalmente en el cultivo de yerba mate, a lo que algunos fueron sumando las plantaciones de tabaco, tung o arroz.

En las primeras décadas del siglo XX, los polacos empezaron a radicarse también en la ciudad de Córdoba, donde muchos fueron contratados en la fábrica de cemento Portland, perteneciente al inmigrante italiano Juan Minetti. El desarrollo de la industria cementera y la consiguiente demanda de mano de obra provocaron que en los años 1927-1930 aproximadamente un $10 \%$ de todos los ciudadanos polacos arribados en este periodo a Argentina se instalaran en Córdoba. ${ }^{29}$ En la misma época, tras el descubrimiento de petróleo en la provincia de Chubut, un grupo de obreros especializados en la industria petrolera, provenientes de la región de Subcarpacia, fue contratado en los trabajos de extracción. En 1935 el número de obreros de este origen residentes en las proximidades de la ciudad de Comodoro Rivadavia alcanzó 250 personas. ${ }^{30}$ Varios de ellos trajeron a sus familias. Desde la década del veinte, los polacos se dirigían también a la ciudad de Santa Fe o a Rosario, donde muchos encontraron trabajo en el frigorífico Swift.

A pesar de las intenciones de los respectivos gobiernos argentinos de redirigir los movimientos migratorios hacia las zonas menos pobladas del

27 Stemplowski, 2011.

28 Mazurek, 2006, 106.

29 Vera de Flachs y Manachino, 2001, 199.

30 Trybus, 1935. 
país, la mayoría de los inmigrantes demostró una acusada preferencia por la ciudad de Buenos Aires y las localidades colindantes. Este también fue el caso que estamos analizando. Desde las últimas décadas del siglo XIX, la capital argentina fue el principal destino de los polacos. Inicialmente, Buenos Aires albergó a militares, abogados, médicos, que llegaron a Argentina después de una de las movilizaciones independentistas fracasadas que estallaron en Polonia a lo largo del siglo XIX. En las primeras décadas del siglo XX a la capital argentina ingresaron también los representantes de la denominada inmigración de «post-revolución», originada por la agitación política y una fuerte oleada de represiones desatadas en el Imperio Ruso en $1905 .{ }^{31}$ Los pertenecientes a este grupo eran principalmente obreros y artesanos de Varsovia, Lublin o Łódź. ${ }^{32}$ En el periodo de entreguerras, a los grupos anteriores se sumaron individuos de diferentes oficios: campesinos, obreros, manufactureros, artesanos, así como el reducido número de funcionarios de las entidades diplomáticas y financieras polacas.

Los ciudadanos polacos no solo se radicaron en la capital, sino principalmente en las ciudades industriales de la provincia de Buenos Aires. Ya a inicios de la década del veinte, en la ciudad de Berisso vivían cuatrocientos inmigrantes polacos ${ }^{33}$ número que fue creciendo en los años posteriores. $\mathrm{Su}$ presencia en la zona fue impulsada por la apertura de los gigantescos frigoríficos —en 1907 de Swift y en 1915 de Armour-, donde muchos encontraron empleo. Los polacos se hicieron visibles también en los ámbitos periféricos de la capital. La apertura, en 1908, en Llavallol de la planta cervecera del empresario alemán Emilio Bieckert, influyó en su establecimiento en la zona. ${ }^{34}$ En este caso, la contratación de los ciudadanos polacos fue favorecida por el director de la fábrica, Gastón Mazurkiewicz, ciudadano frances de ascendencia polaca que demostró una clara predilección por contratar a sus connacionales. A principios de los años treinta, en Llavallol residían veinticinco familias y doscientos hombres de origen polaco. ${ }^{35} \mathrm{En}$ la misma época, la posibilidad de encontrar empleo en los trabajos portuarios incentivó la instalación de los ciudadanos polacos en Dock Sud. La presencia polaca en la zona sur de la capital fue fomentada, además, por la inauguración en 1927 del frigorífico Anglo. Según las fuentes comunitarias, el

31 Smolana, 1996, 43.

32 Mazurek, 2006, 87.

33 Włodek, 1923, 404.

34 Llavallol, 1992, 89-92.

35 Kalendarz-Informator, 1931, 121. 
número de polacos radicados en Dock Sud al inicio de la década del treinta superaba las dos mil personas. ${ }^{36} \mathrm{La}$ industria frigorífica también determinó el establecimiento de un grupo de polacos en Valentín Alsina, donde muchos fueron contratados en el frigorífico Wilson. ${ }^{37}$

La existencia y el crecimiento de las comunidades polacas en ciertas ciudades y la concentración étnica en un sector comprueba la importancia de las relaciones interpersonales a la hora de acceder a un determinado trabajo. Muchos obreros polacos, al igual que en el caso de otros grupos étnicos ${ }^{38}$ fueron reclutados a través de las relaciones personales, gracias a las recomendaciones de parientes o paisanos que actuaron como mediadores en el proceso de contratación. No obstante, teniendo en cuenta la escala del fenómeno, la mayoría de los recién llegados en los últimos años de la década del veinte y los primeros del treinta no pudo beneficiarse de los vínculos de paisanaje existentes.

No disponemos de las estadísticas exactas sobre la estructura ocupacional de los polacos en la Argentina de entreguerras. No obstante, los datos fragmentarios presentados por el Patronato - agencia de colocación fundada en la ciudad de Buenos Aires en 1928 y dependiente de la Oficina de Emigración en Polonia- demuestran que, en 1928, la mayoría de los ciudadanos polacos que solicitaron la intermediación en la búsqueda de trabajo (el $55 \%$ ) quedó contratada en las cuadrillas de construcción de las vías férreas y en las obras subterráneas. Un porcentaje significativo, el 12 $\%$, fue contratado en las canteras y en los trabajos agrícolas, el $10 \%$ en el sector de la construcción, otro $10 \%$ en el servicio doméstico y el resto en distintas ramas del trabajo artesanal. ${ }^{39}$ Como podemos observar, si bien la profesión declarada por la mayoría en el lugar de origen estaba ligada al sector de la agricultura, los datos señalados demuestran un importante cambio ocupacional dentro del grupo.

El periodo de entreguerras corresponde también al desarrollo de las estructuras asociativas polacas. En el año 1918, en la ciudad de Buenos Aires,

36 Ibidem, 117.

37 «W Valentin Alsina powstało nowe Towarzystwo Polskie», Głos Polski, 30 de junio de $1934,19$.

38 La importancia de las redes familiares y de paisanaje a la hora de desplazarse de un lugar a otro y en el proceso de reclutamiento fue analizada, por ejemplo, en el caso de los obreros italianos contratados en la fábrica Pirelli (véase Barbero y Felder, 1992) o en el de los inmigrantes empleados en la Algodonera Flandria y la Fábrica Argentina de Alpargatas (véase Ceva, 2010a). Lo demuestra también el caso de los polacos judíos, del que hablaremos más adelante.

39 Klarner-Kosińska, 1983, 229-231. 
tras la unión de dos sociedades ya existentes con el objetivo de conmemorar la recuperación de la independencia, fue creada la asociación «Polonia Libre» («Wolna Polska»). En 1926, también en la capital, se fundó la Sociedad «Casa Polaca» (Towarzystwo «Dom Polski») y en 1930 el «Hogar Polaco» («Ognisko Polskie»). De la misma forma, el establecimiento de los polacos en las afueras de la capital y en las ciudades cercanas favoreció la aparición de nuevas entidades. En 1913 se creó la Sociedad Polaca de Berisso, denominada posteriormente la Unión Polaca en Berisso. En 1926 los polacos de Dock Sud y Llavallol tomaron la decisión de asociarse y en 1934 lo hicieron también los de Valentín Alsina. Paralelamente, a finales de la década del veinte, entre los representantes de la colectividad polaca bonaerense surgió la iniciativa de establecer un órgano central que apoyara las acciones de los grupos locales y favoreciera su colaboración. Como resultado, en 1929 se fundó la Federación de Sociedades y Asociaciones «Casa Polaca». En su inicio las actividades de las respectivas asociaciones, así como del organismo central, estaban enfocadas principalmente en la esfera de lo cultural, educativo y recreativo. No obstante, las evidencias de la crisis económica y la elevada desocupación entre los inmigrantes polacos obligaron a ampliar sus acciones hacia la ayuda mutua y la beneficencia.

La aparición de varias asociaciones polacas en el periodo de entreguerras no fue acompañada por una alta participación en las estructuras colectivas. Se calcula que al principio de los años treinta, el número de todos los afiliados a las entidades voluntarias polacas en Argentina, incluida la provincia de Misiones, no superaba las mil personas. ${ }^{40}$ En la misma época, el Centro Gallego ya había llegado a los 27.000, mientras que la Asociación Española de Socorros Mutuos contaba con 31.000 afiliados. ${ }^{41}$ En el caso polaco, los frecuentes cambios residenciales y ocupacionales de un porcentaje sustancial de los inmigrantes ciertamente afectaron las estructuras comunitarias. La muy escasa participación de los inmigrantes polacos en las estructuras asociativas parece comprobar, además, que el asociacionismo tiende a atraer sobre todo a migrantes estables, con mejores ocupaciones y mayores ingresos, por lo que no tienen dificultades para cumplimentar el pago de las cuotas exigidas. ${ }^{42}$ Por otro lado, el poco interés por asociarse de los inmigrantes polacos probablemente indica que los servicios brindados por las respectivas entidades no tenían la capacidad de proporcionarles

40 Klarner-Kosińska, 1983, 227.

41 Fernández, 2008, 493.

42 Ibidem, 494. 
beneficios concretos que compensaran el esfuerzo económico que implicaba la membresía. Asimismo, una muy alta conflictividad entre los dirigentes de los respectivos centros, muy presente en toda la década del treinta, constituyó indudablemente otro factor desalentador.

\section{La crisis económica de 1929}

El estallido en 1929 de la crisis en los Estados Unidos pronto se expandió a prácticamente todo el mundo industrializado, inaugurando el periodo denominado la Gran Depresión. También Argentina tuvo que enfrentarse a una bajada de precios de sus principales productos de exportación. ${ }^{43} \mathrm{La}$ desvalorización de la producción agrícola, junto con las medidas proteccionistas empleadas por los países receptores, ocasionaron, a su vez, una drástica reducción de la capacidad de importación, provocaron dificultades para obtener nuevas inversiones del capital y se reflejaron en el notable descenso de la actividad económica. ${ }^{44}$ A eso habría que añadir la pérdida de cosechas debido a los prolongados periodos de sequía y las devastaciones ocasionadas por la langosta, plaga que el país sufrió al principio de la década del treinta. ${ }^{45} \mathrm{El}$ resultado más inmediato de la depresión fue una prolongada caída de la actividad económica, la disminución de los salarios y el aumento de la desocupación. El sueldo promedio de los obreros industriales, si tomamos el índice del año 1929 como 100, cayó a 81 en 1932 y a 77 en $1934 .{ }^{46}$ La importante reducción de los salarios y la creciente desocupación fueron acompañadas por un fuerte aumento de los costos de manutención y, seguidamente, por un deterioro generalizado de los niveles de vida. Aunque la inestabilidad de la actividad laboral formaba parte de la experiencia habitual del obrero argentino de finales del siglo XIX y principios del XX, el crecimiento económico experimentado por el país en la década del veinte se tradujo en la estabilización del empleo. Al mismo tiempo, se consiguieron importantes avances en la materia de la legislación laboral, estableciendo una jornada laboral de ocho horas diarias y cuarenta horas semanales. Es por ello por lo que el notable deterioro de las condiciones laborales y el aumento de la desocupación registrado al iniciarse la década del treinta despertaron mayores preocupaciones que las crisis anteriores.

43 Korol, 2001, 22.

44 Ceva, 2010b, 90.

45 Junta Nacional para Combatir la Desocupación, Memoria 1937, Buenos Aires, 1938, 17.

46 González Leandri, 2001, 212. 
Existen diferentes estimaciones referentes a la escala del problema de la desocupación en el periodo analizado. En 1932, por iniciativa del Departamento Nacional del Trabajo, se llevó a cabo el Censo Nacional de los Desocupados ${ }^{47}$ Según los resultados obtenidos, del total de la población, que por esta fecha alcanzaba once millones de habitantes, aproximadamente 334.000 se declaraban desocupados; es decir, 2,4 \% de la población total. En cuanto a la división por nacionalidad, después de los argentinos (225.262 desocupados), la mayor cantidad correspondía a los italianos (41.423) y españoles (28.763), seguidos por los polacos: 9.514. Los resultados del censo, al depender de la voluntad de los individuos de registrarse y reconocer su estatus de desocupados, eran altamente cuestionables. ${ }^{48}$ No faltaron voces, incluso de los propios funcionarios a cargo del censo, señalando que las cifras obtenidas estaban muy por debajo de la realidad. Según otras estimaciones, la desocupación en este mismo periodo pudo haber alcanzado un $28 \%$ de la población laboralmente activa ${ }^{49}$ En lo que sí existe un consenso es sobre los sectores más afectados por la depresión económica. Los más perjudicados, aproximadamente un $40 \%$ del total de los desocupados, fueron los trabajadores del sector agrícola, seguidos por los trabajadores de la industria, transporte y servicios portuarios, casi un $30 \%$, y por los obreros de la construcción, un $12 \% .{ }^{50}$

El impacto de la crisis se hizo particularmente visible en las grandes ciudades y, sobre todo, en Buenos Aires. En el periodo de entreguerras la capital argentina cobijaba en su seno al $40 \%$ de todos los trabajadores industriales de la República. ${ }^{51}$ Además, ante la caída de la actividad en el campo, los trabajadores del sector agrícola empezaron a acudir masivamente a la ciudad en busca del empleo. Como consecuencia, desde el inicio de la década del treinta, en el paisaje urbano bonaerense se hicieron presentes los asentamientos informales de las personas sin techo. Este fue el caso de los campamentos formados en los bosques de Palermo, en el Parque Patricios, Villa Pueyrredón y en el Bajo Belgrano. El más numeroso, sin embargo, fue el popularmente denominado «Villa Desocupación» o «Villa Esperanza», establecido en la zona del Puerto Nuevo. ${ }^{52}$ Instalados inicialmente en los galpones vacíos del puerto, los desocupados pronto comenzaron a

47 Panettieri, 1996, 19-20.

48 Girbal-Blacha, 2003, 27.

49 Korol, 2001, 23-24.

50 Panettieri, 1996, 20.

51 González Leandri, 2001, 204.

52 Snitcofsky, 2013, 96. 
expandirse y a poblar los terrenos baldíos de la costa del Río de la Plata. Con los materiales donados por las autoridades porteñas, fueron construyendo lo que un testigo ocular de la época definió como «pequeñas, bajas y antihigiénicas casuchas». ${ }^{53}$ Pese a su carácter rudimentario, el campamento no estuvo exento de una cierta organización. Algunos de los habitantes emprendieron sus propios negocios, como cigarrerías, peluquerías, pequeños almacenes con productos alimenticios, o las tan criticadas quinielas. ${ }^{54} \mathrm{El}$ asentamiento siguió creciendo y ya en 1934 el número de sus habitantes alcanzó cinco mil personas. ${ }^{55}$ La mayoría eran hombres, jóvenes o de mediana edad, casi todos de origen extranjero. ${ }^{56}$ Los desocupados crearon sus propias secciones, que reflejaron una división según la nacionalidad. Como señalaban distintas fuentes, el número de los ciudadanos polacos instalados en la Villa Desocupación oscilaba entre un 30 y un $50 \% .{ }^{57}$

\section{El impacto de la crisis económica entre los inmigrantes polacos}

Según las estimaciones de Klarner Kosińska, en el año 1930 la tercera parte de todos los inmigrantes polacos residentes en Argentina se encontraba sin trabajo y los que consiguieron conservar el empleo trabajaban de forma discontinua o sufrían grandes cortes en el salario. ${ }^{58}$ Esta situación se deterioró sucesivamente en los años siguientes, alcanzando su apogeo en 1933. Las fuentes étnicas señalaban que en este periodo el número de obreros desocupados superaba el $50 \%$. Probablemente el desempleo no llegó a tales dimensiones, pero con toda seguridad estaba por encima de los cálculos ofrecidos por el Censo Nacional de los Desocupados llevado a cabo por el Departamento Nacional del Trabajo. El sucesivo deterioro de la situación laboral lo demuestran también las estadísticas presentadas por el Patronato. En el año 1930, en la sede bonaerense de la agencia polaca de colocación fueron presentadas 5.977 solicitudes de intermediación en la búsqueda de trabajo, de las que se resolvieron favorablemente $706 .{ }^{59}$ En el periodo de

53 Ré, 1938, 66.

54 Quiniela: un juego de azar de carácter ilegal. A pesar de la persecución policial, el juego gozó de gran popularidad en la Argentina de entreguerras.

55 Iñigo Carrera y Fernández, 2007.

56 Ré, 1938, 68.

57 Klarner-Kosińska, 1983, 233.

58 Ibidem, 232.

59 Idem. 
siete meses, desde el 1 de octubre de 1931 hasta el 1 de mayo de 1932, el número de solicitudes creció hasta 7.113, de las que 870 personas consiguieron trabajo. ${ }^{60}$ En 1933, tan solo en el mes de junio 1.288 desocupados acudieron a la oficina, de los que menos de un $10 \%$ consiguió colocación. ${ }^{61}$ Entre los que acudían a la entidad en busca de ayuda no faltaban quejas que denunciaban que los trabajos a los que la entidad brindaba acceso eran los peor pagados, los más peligrosos y la mayoría implicaba el traslado al interior del país. En consecuencia, muchos de los obreros no soportaban la precariedad existente, ni las pésimas condiciones de empleo y tras unas pocas semanas de trabajo regresaban a la ciudad de Buenos Aires.

La inestabilidad vivida por los trabajadores de este origen fue un tema recurrente en las notas, no exentas de una fuerte carga emotiva, publicadas por la prensa polaca de Buenos Aires. En las páginas de los periódicos abundan las imágenes de centenares de inmigrantes polacos sin ocupación, desnutridos, deambulando por las calles porteñas. Según señalan las fuentes étnicas, esta situación empeoraba en los meses de invierno, cuando, una vez terminada la cosecha, acudían a la capital miles de jornaleros. No faltaron voces que por las penurias vividas por los trabajadores polacos culpaban a las autoridades del país de origen y, sobre todo, a una falsa imagen de Argentina - como un país de enormes riquezas y de grandes posibilidades- que se siguió propagando en Polonia aun cuando ya resultó evidente que el mercado laboral argentino había perdido su capacidad de ofrecer trabajo:

Los últimos transportes de emigrantes provenientes de Polonia, que desembarcaron en las orillas argentinas, despiertan la sensación que Polonia pretende mandar a todos sus habitantes fuera del país; no existe ni la más mínima selección entre los dispuestos a emigrar. Se envía a la gente, peor aún, familias enteras, que no están preparadas para establecerse en Argentina o en Paraguay. [...] Todos ellos atraídos por las perspectivas color de rosa, que les fueron transmitidas por los agitadores emigratorios que están deambulando por el país. ${ }^{62}$

Paralelamente, la prensa étnica alertaba sobre el creciente fenómeno de mendicidad entre los polacos e informaba sobre cientos de connacionales viviendo de limosna en las proximidades de la Villa Desocupación y en

\footnotetext{
60 «Działalność Patronatu Polskiego», Gtos Polski, 19 de junio de 1932, 7.

61 «Sprawozdanie z czynności Patronatu Polskiego w Buenos Aires za miesi c czerwiec 1933 roku», Gtos Polski, 15 de julio de 1933, 8.

62 «Naga Prawda. Skandal Emigracyjny», Gtos Polski, 22 de agosto de 1936, 2. [Traducción de la autora].
} 
el centro de la ciudad. Ante la cada vez mayor visibilidad del problema, el gobierno argentino optó por tomar medidas represivas. Ya el 15 de julio de 1932 fue aprobada la ley según la cual los mendigos o los que explotasen la mendicidad podían quedar reprimidos con una multa de 20 a 70 pesos o con el arresto de 6 a 21 días. El análisis de las fuentes policiales confirma el protagonismo que en el ejercicio de la mendicidad desempeñaban los individuos de origen extranjero, destacando dentro de este grupo los ciudadanos polacos. En el año 1933, 440 personas de esta nacionalidad quedaron detenidas por ejercer la mendicidad en la capital, número que superó las detenciones registradas entre los representantes de los grupos migratorios mayoritarios. A modo de comparación, en el mismo año fueron detenidos 316 españoles y 265 italianos. ${ }^{63}$

A la creciente mendicidad, a finales del año 1933 y principios de 1934, se sumó la participación de los habitantes de la Villa Desocupación en una serie de atracos a almacenes y tiendas alimenticias, localizadas en la proximidad del Puerto Nuevo. Los sucesos fueron protagonizados por individuos armados de revólveres, hierros y piedras, que ocasionaron importantes daños materiales en los negocios de la zona. Todos los detenidos fueron identificados como ciudadanos polacos. ${ }^{64}$ Ante los actos delictivos, las autoridades se vieron obligadas a tomar medidas drásticas. En enero de 1934 los obreros municipales procedieron al derrumbe del asentamiento. Tras la intervención de los funcionarios de la policía, los desocupados con antecedentes penales quedaron encarcelados y los demás fueron obligados a trasladarse a los albergues oficiales en las proximidades del Puerto Nuevo ${ }^{65}$ En estas circunstancias, no faltaron opiniones que señalaban que las dificultades que experimentaban los polacos a la hora de incorporarse a las estructuras existentes del país eran resultado directo de la etapa preemigratoria. De acuerdo con estas ideas, Juan Alejandro Ré, subcomisario en la comisaría 23, bajo cuya jurisdicción permaneció la Villa Desocupación, afirmaba que a partir de la I Guerra Mundial,

nuestro país presenció impasible la invasión pacífica de gente extranjera, de todas las nacionalidades —especialmente polaca—, gente que en su mayoría por su condición de ex combatientes, traía consigo taras patológicas y carencia absoluta de recursos de subsistencia. ${ }^{66}$

63 Ré, 1938, 68-69.

64 «Noticias de policía», La Prensa, 4 de noviembre de 1933, 12.

65 Ré, 1938, 78.

66 Ibidem, 65. 
De este modo, el hecho de haber pasado por las experiencias de la guerra les condenaba, según esta línea argumentativa, a ser portadores de trastornos mentales y, por tanto, imposibilitaba su integración a la sociedad argentina.

La presencia polaca entre los grupos más perjudicados por las secuelas de la gran crisis económica también fue destacada por los actores argentinos. Algunos de ellos incluso se plantearon el porqué de la tan alta vulnerabilidad de los trabajadores de este origen en comparación con otros grupos étnicos. En un intento de contestar dicha interrogante, Felipe Sahores, el gerente del albergue donde quedaron alojados los desocupados tras el derribo de la Villa Desocupación, señalaba:

Predominaban los extranjeros, y entre ellos ocupaban los primeros términos los polacos, italianos y españoles. No podría explicarse la razón del gran número de polacos, cuando los hombres de esta nacionalidad, en la población del país y en relación con la de italianos y españoles, son una ínfima minoría. Existía, sin embargo, una que justificaba esa mayoría de polacos y gran número de checo-eslovacos y lituanos: para los trabajos de un subterráneo, la empresa constructora había contratado peones de esas nacionalidades y, al terminar la obra, todos esos obreros, que habían trabajado muchos meses con jornales reducidos, vale decir, sin poder realizar economías apreciables [...], se encontraron en un país donde no tenían hogar constituido, carentes de recursos y de vinculaciones, sin trabajo y sin posibilidad de conseguirlo, ya que la terminación de la obra coincidió con el período de crisis aguda. ${ }^{67}$

Este fragmento señala, acertadamente, varios elementos que influyeron en esta situación. Como ya se ha apuntado, en la primera etapa de la experiencia migratoria los polacos eran contratados en los trabajos manuales de menor calificación, que no requerían conocimiento de la lengua. Al mismo tiempo, el empleo al que podían acceder era aquel que se caracterizaba por una gran inestabilidad y una fuerte rotación del personal. Este era el caso, por ejemplo, de la construcción de caminos o túneles para los trenes subterráneos, de las tareas agrícolas dependientes del calendario estacional y también del trabajo en los frigoríficos, donde los ritmos y la intensidad laboral variaban de acuerdo con las necesidades de la industria y del mercado. ${ }^{68}$

En este sentido, la alta vulnerabilidad de los inmigrantes polacos, en comparación con los demás grupos étnicos, estaba relacionada, en parte, con el poco tiempo de permanencia en el país antes del estallido de la gran

67 Junta Nacional para Combatir la Desocupación, Memoria 1937, Buenos Aires, 1938, 37.

68 Como señala Mirta Lobato, en el frigorífico Swift de Berisso el número de varones que trabajaban menos de un año alcanzaba un $83 \%$ del total de los trabajadores y en Armour un 50,2\% (Lobato, 2001, 211-12). 
crisis económica. Si comparamos el caso polaco con el de otros grupos de origen inmigrante podemos ver, por ejemplo, que la mayor afluencia de los grupos mayoritarios, italianos y españoles, al igual que los rusos, tuvo lugar en el periodo 1906-1910 y la de los alemanes en el lustro de 1921-1925. ${ }^{69}$ Como ya se ha señalado, el espectacular crecimiento de la presencia polaca en Argentina tuvo lugar en los años anteriores a la Gran Depresión, por tanto muchos inmigrantes no tuvieron tiempo para alcanzar una estabilidad laboral suficiente que les permitiera afrontar los resultados de la crisis. En consecuencia, el factor tiempo determinó su escasa integración laboral que se hizo particularmente visible en el momento de la caída de la actividad económica. Por otro lado, el acceso al mercado de trabajo limitado a los puestos más bajos en la jerarquía laboral, también estuvo relacionado con la debilidad de las redes sociales. ${ }^{70}$ Una fuerte reorientación de los movimientos migratorios polacos hacia Argentina, resultado de las restricciones en la política migratoria estadounidense, superó las escasas posibilidades de los vínculos de paisanaje existentes. Por ello, al no disponer de lazos con otros inmigrantes ya establecidos en el país, la mayoría de los recién llegados dependía de los mecanismos impersonales de contratación y de los trabajos al que estos ofrecían acceso.

\section{La comunidad polaca ante la crisis}

Dado el impacto que la crisis económica tuvo entre los inmigrantes polacos, las estructuras asociativas con el apoyo del cuerpo consular se vieron obligadas a emprender una serie de actividades que paliaran la situación de los connacionales más desfavorecidos. Las primeras acciones asistenciales fueron desarrolladas por el ya mencionado Patronato, cuyas funciones, además de actuar como agencia de colocación, consistían en servir de apoyo jurídico o sanitario, intermediar entre el empresario y el trabajador, ayudar a las personas sin recursos e incluso facilitar, en casos extremos, el retorno a Polonia. La escalada de la crisis claramente superó las escasas posibilidades del Patronato. Según los informes presentados por la institución, apenas un $15 \%$ de los ciudadanos polacos pudo contar con su apoyo. Tampoco cumplió su función el albergue para los desocupados, fundado

69 «Cuadro de inmigrantes llegados a Argentina, 1857-1956», Memoria de la Dirección de Migraciones, Buenos Aires, CEMLA, 1956.

70 Devoto, 2009, 366. 
en 1928 gracias a las colectas realizadas por los inmigrantes. El edificio, situado en el barrio porteño de Flores, tenía la capacidad de alojar hasta 120 personas. ${ }^{71}$ La iniciativa, sin embargo, no tuvo buena acogida entre los propios inmigrantes. La constante falta de medios financieros para el mantenimiento, su distancia del centro y de las principales entidades polacas, la falta de higiene básica, además de grandes defectos en su construcción, provocaron que el albergue se ganara el nombre de «El Hotel Miseria».

Paralelamente, a comienzos de 1931, en las cercanías a la zona de Retiro, detectada como la de mayor concentración de polacos desocupados, fue abierto el comedor gratuito, con el apoyo del cuerpo diplomático y gracias a donaciones privadas. El día de la apertura, los iniciadores del proyecto aseguraban con gran entusiasmo que este podría ofrecer hasta seiscientos almuerzos diarios y que era una solución definitiva para la desnutrición de los compatriotas. En realidad, debido a la escasez de fondos económicos, no llegaba a preparar más de ciento cincuenta comidas al día. Además de la acción benéfica, a través del comedor gratuito se intentó poner en práctica medidas correccionales. Los empleados del comedor recibieron instrucciones en las que se les prohibía distribuir almuerzos a aquellos que se hubieran negado a aceptar el trabajo que el Patronato ofrecía, ya que, según podemos leer en el informe ofrecido por la entidad: «El comedor gratuito fue fundado para inmigrantes pobres pero trabajadores, y no para vagos y vagabundos».$^{72}$ Con esta exclusión ejemplificadora, se pretendía disuadir a los inmigrantes de su estancia prolongada en Buenos Aires y se les obligaba a aceptar cualquier empleo disponible, independientemente del lugar y las condiciones que ofreciera. Pese al entusiasmo inicial con que fue recibido, el proyecto no sobrevivió mucho tiempo. El cada vez menos generoso número de donaciones provocó que el comedor gratuito de Retiro cerrara sus puertas en noviembre de $1931 .^{73}$

Dada la perdurabilidad de la crisis, en 1933, por iniciativa de los miembros más activos de la comunidad y con el apoyo de todas las asociaciones polacas de Buenos Aires, se fundó el Comité de Ayuda a los Desocupados. La nueva institución, por un lado, pretendía reunir fondos para satisfacer las necesidades más inmediatas de los inmigrantes, garantizarles el acceso

71 Białobrzeski y Szel gowskI, «Sprawozdanie z Działalności Towarzystwa Dom Polski», Gtos Polski, 24 de junio de 1928, 4.

72 «Sprawozdanie cyfrowe bezpłatnej jadłodajni przy Zw. Tow. Dom Polski», Glos Polski, 5 de abril de 1931, 4. [Traducción de la autora].

73 «Odezwa», Gtos Polski, 22 de noviembre de 1931, 1. 
a alimentos y ofrecer ropa o productos de higiene básica y, por otro lado, dada la inoperancia del Patronato, se comprometía a aumentar los esfuerzos en la búsqueda de empleo para los desocupados y brindarles información práctica sobre oportunidades existentes. ${ }^{74}$ En este sentido, el nordeste argentino, donde desde la última década del siglo XIX iban estableciéndose los colonos polacos, se presentaba como una posibilidad viable para escapar de la miseria vivida en las grandes ciudades. En la prensa polaca de la época no faltaron los encendidos llamamientos a «nuestros hermanos polacos de Misiones», que apelaban a la solidaridad para ayudar a compatriotas desocupados, al tiempo que enumeraban las ventajas que ofrecía la colonización en la tierra misionera. No obstante, la crisis económica también afectó a las colectividades polacas en Misiones y, particularmente, a la industria yerbatera, una de las principales fuentes de ingreso de los colonos polacos. La caída de los precios impactó seriamente en la producción y comercialización de yerba mate y los colonos perdieron la capacidad de contratar mano de obra asalariada. ${ }^{75}$

Además de proyectos conjuntos, organizados entre varias entidades con el apoyo del cuerpo diplomático, las respectivas asociaciones emprendieron acciones a menor escala. En los años más duros de la crisis se procedió al financiamiento de entierros de paisanos sin medios económicos, se organizaron bolsas de comida o se prestó ayuda económica a personas sin recursos. No obstante, la capacidad asistencial de los respectivos centros era mínima. Para dar un ejemplo de su escaso impacto, en el periodo de mayo de 1931 a abril de 1932, la Unión Polaca en Berisso otorgó subsidios para once personas $(93,55$ pesos) y la Sociedad Polaca en Dock Sud ayudó a ocho personas, con subsidios de 52 pesos. ${ }^{76}$ Por esa misma fecha, el salario mensual medio de un obrero industrial superaba ligeramente los cien pesos.

Los principales perjudicados no permanecieron inmóviles ante la situación en la que se encontraban. En agosto de 1933 entre los habitantes de la Villa Desocupación se formó el Comité de Polacos Desocupados. Su principal objetivo era representar a los connacionales sin trabajo. En los llamamientos publicados en la prensa étnica, los desocupados reclamaban el consenso entre las asociaciones y el trabajo conjunto para mejorar la situación de los ciudadanos polacos. Exigían, además, intermediación fructífera

74 «Ukonstytuował się Komitet Pomocy Bezrobotnym», Głos Polski, 30 de agosto de 1933, 1.

75 Gelman y Barsky, 2009.

76 « ruchu Towarzystw», Codzienny Niezależny Kurier Polski w Argentynie, 13 de agosto de 1932, 6 . 
en la búsqueda de trabajo y, si esta exigencia era imposible de cumplir, solicitaban ayuda económica para retornar al país. ${ }^{77}$ A pesar de la incapacidad de la colectividad para brindar asistencia a los desocupados, el retorno no fue contemplado como una forma de ayuda. Tanto las oficinas consulares como la prensa étnica desaconsejaban retornar a Polonia, argumentando que la situación vivida en el país de origen era mucho peor. Consecuentemente, todas las solicitudes dirigidas al Patronato con el fin de financiar el retorno fueron denegadas. De los dos mil retornos anuales que se produjeron durante los años de mayor crisis, la mayoría lo hizo por sus propios medios. ${ }^{78}$

\section{La colectividad judeo-polaca ante la crisis}

Al analizar el impacto de la crisis económica en la década de los treinta sobre la inmigración proveniente de Polonia, no se puede ignorar una parte sustancial de la misma, es decir, la de los polacos judíos. Como se ha señalado, en el periodo de entreguerras, los judeo-polacos fueron la tercera parte del total de inmigrantes de esta nacionalidad, al tiempo que constituyeron un porcentaje sustancial del conjunto de los judíos residentes en Argentina. A finales de los años treinta, el $22 \%$ de la totalidad de los judíos procedía de Polonia y, en el caso de Buenos Aires, este porcentaje se elevaba al $31 \% .^{79} \mathrm{Si}$ bien en los datos estadísticos los judíos fueron tratados conjuntamente con los demás ciudadanos polacos, las características del grupo eran muy diferentes del resto de inmigrantes provenientes de Polonia. Por ello, a la hora de analizar las secuelas de la crisis económica, los judeo-polacos requieren ser examinados por separado.

A diferencia de los polacos católicos, la inmigración judía tuvo un carácter mayoritariamente familiar. Se trataba de personas provenientes de un ámbito urbano y con expectativas de retorno muy bajas. El auge de la migración judía fue anterior al de los polacos católicos. El mayor número, 7.500 ingresos $(75 \%$ del total de los ciudadanos polacos ingresados a Argentina), fue registrado en el año 1923. Desde entonces y hasta el estallido de la crisis, la migración judía empezó a disminuir sistemáticamente (4.700 en 1926 y 3.800 ingresos en 1929). ${ }^{80} \mathrm{El}$ significativo descenso —en comparación con la tendencia ascendente de la inmigración polaca- es-

77 «Z Palerma», Codzienny Niezależny Kurier Polski, 6 de diciembre de 1933, 3.

78 Janowska, 1984, 388.

79 Kowalska, 1989, 258.

80 Ibidem, 259. 
taba relacionado con la reorientación del movimiento migratorio; desde la segunda mitad de los años veinte, creció considerablemente la inmigración judía hacia Palestina.

Los arribados a Argentina en el periodo de entreguerras optaron por radicarse principalmente en las grandes ciudades, la mayoría en la capital y tan solo un $11 \%$ se dirigió a las colonias agrícolas. ${ }^{81}$ Dentro de la ciudad de Buenos Aires, los polacos judíos se fueron estableciendo en Villa Crespo, Villa Devoto, Belgrano, en menor grado en el barrio Once y, desde la segunda mitad de la década de los veinte, también en las suburbanas Vicente López y Villa Lynch. ${ }^{82}$ Entre las profesiones ejercidas, predominaron comerciantes, vendedores ambulantes, manufactureros, artesanos y obreros. Un porcentaje sustancial se dedicó a la industria textil. Este fue el caso de los inmigrantes judíos provenientes de las ciudades de Białystok, Łódź y Bełchatów, donde desde el siglo XIX se había desarrollado la industria textil a gran escala. Los procedentes de estas regiones, en su mayoría expertos tejedores, encontraban su primer empleo en las fábricas textiles de Campomar en el barrio de Belgrano, o en Braceras en la zona de Vicente López.

La estrategia laboral consistía en trabajar un tiempo en relación de dependencia y, tras ganar el capital suficiente, fundar su propio taller textil. Con el tiempo las pequeñas fábricas, de las que muchas fueron instaladas en Villa Lynch, se transformaron en medianas empresas textiles. Es allí donde, a su vez, se contrataba a familiares y vecinos provenientes de Polonia. ${ }^{83}$ Asimismo, como señala Bargman, a través de la industria y el comercio textil, los judeo-polacos establecieron una importante articulación con el contexto argentino y aseguraron su movilidad social ascendente. ${ }^{84}$ En consecuencia, su trayectoria colectiva en el periodo analizado fue más exitosa que la del resto de los ciudadanos polacos, característica que también fue registrada por los representantes del cuerpo diplomático polaco. Ya a principios de los años veinte, el cónsul polaco, Józef Włodek, apuntaba:

En las relaciones locales se orientan rápidamente y poco después de llegar ya se dedican a hacer negocios [...]. Consiguieron establecerse en todos los principales distritos de Buenos Aires, con preferencia en aquellas avenidas, donde existen perspectivas de mejor desarrollo [...]. También se metieron en los barrios aristocráticos de Palermo y Belgrano, donde adquirieron sus propios palacios [...]. Gracias a sus contactos, llegan

81 Ibidem, 261.

82 Bargman, 2011, 178.

83 Trybiarz, 2006.

84 Bargman, 2011, 180. 
a las más altas autoridades y consiguen influencia en las agencias nacionales. El conocimiento de idiomas extranjeros les facilita encontrar trabajo y, hoy en día, en la mayoría de las oficinas argentinas, con facilidad se encuentra a un judío. ${ }^{85}$

Paralelamente, los polacos judíos demostraron una mayor predisposición que sus conciudadanos católicos para fundar asociaciones étnicas. En los años treinta, tan solo en la ciudad de Buenos Aires, existían doce asociaciones judías que reflejaban diferentes regiones polacas de las que procedían sus afiliados. Los socios de cinco de ellas de las que tenemos datos - aproximadamente mil personas — igualaban en número a todos los afiliados de las organizaciones polacas católicas en el territorio argentino. ${ }^{86}$ Ninguna de las entidades judías perteneció a la Federación de Sociedades y Asociaciones «Casa Polaca», creando su propio organismo central denominado «Unión Israelita Polaca». Además de las asociaciones regionales, hacia 1930 se desarrollaron varias instituciones de ayuda mutua, socorro y beneficencia - tanto religiosas como seculares-, que reunían a judíos procedentes de diferentes países de la Europa Centro-oriental.

Ya en 1894, en la ciudad de Buenos Aires, se había creado la Jevra Kedushá Ashkenazí, denominada posteriormente como Asociación Mutual Israelita Argentina (AMIA). Inicialmente su objetivo consistía en atender las inhumaciones de los afiliados conforme al rito judío, y con el tiempo se agregaron otras tareas del campo de la beneficencia. En 1928 el número de socios de Jevra Kedushá llegó a superar las catorce mil personas. ${ }^{87}$ En 1900 se fundó la Sociedad Israelita de Beneficencia Ezrah, que en 1932 llegó a contar con casi once mil afiliados. Bajo su iniciativa, en 1921 se construyó el Hospital Israelita. En 1930 el número de pacientes atendidos en sus instalaciones alcanzó las 48.000 personas. ${ }^{88}$ Entre ellos, durante los años más duros de la crisis, se encontraban los polacos católicos, quienes no disponían de un centro médico propio. ${ }^{89} \mathrm{Al}$ mismo tiempo, en los años veinte, existieron en Buenos Aires dos orfanatos y un asilo para ancianos. En 1922 fue establecida la Sociedad Protectora de Inmigrantes Israelitas (SOPROTIMIS), que funcionó como agencia de colocación. Ese mismo año quedó establecida la Cocina Popular Israelita, que proporcionaba comida gratuita o a muy bajo costo a judíos sin recursos. Además, en la mayoría

85 Włodek, 1923, 447. [Traducción de la autora].

86 Kowalska, 1989, 263.

87 Mirelman, 1988, 328.

88 Ibidem, 324-327.

89 «Komunikaty», Niezależny Kurier Polski, 24 de agosto de 1930, 4. 
de las entidades había una sección que proveía subsidios a los más necesitados, ropa y, ocasionalmente, alguna herramienta o máquina de trabajar. ${ }^{90}$ $\mathrm{Si}$ bien las entidades judías no eran ajenas a los conflictos internos, discusiones ideológicas y disputas por el poder entre dirigentes, la colectividad consiguió desarrollar fuertes estructuras colectivas, donde los servicios y las prestaciones brindadas eran muy variadas.

No disponemos de datos exactos sobre el impacto que la crisis económica mundial tuvo sobre los judíos provenientes de Polonia. Tampoco sabemos qué porcentaje de los desocupados polacos se refiere a los judíos. Indudablemente este tema requiere mayores análisis. En cualquier caso, basándonos en las particularidades de los movimientos migratorios de este grupo, sus características socio-demográficas, así como las estructuras asociativas, podemos afirmar que en este caso las secuelas de la crisis fueron menos impactantes que las de los polacos católicos.

Los efectos de la crisis en Argentina perduraron hasta la segunda mitad de los años treinta. A partir de entonces, la economía comenzó a recuperarse paulatinamente. La política económica favoreció la afluencia de capital extranjero, se restableció una tendencia ascendente en las exportaciones y se observó una mejora de los precios en los principales productos destinados a la exportación. La reactivación económica, junto con el espectacular desarrollo de obras públicas, provocaron que el mercado laboral volviera a restablecerse y la desocupación, incluida la de los ciudadanos polacos, fuera disminuyendo progresivamente. Consecuentemente, a la par que las condiciones económicas, empezó a recuperarse el movimiento migratorio entre ambos países. Ya en 1936, aproximadamente seis mil ciudadanos polacos arribaron a Buenos Aires, y un año más tarde este número creció hasta ocho mil quinientos. ${ }^{91}$ No obstante, el estallido de la Segunda Guerra Mundial paralizó casi por completo los movimientos poblacionales, poniendo fin a una época destacable en la historia de la migración polaca hacia Argentina.

\section{Conclusiones}

Como hemos intentado demostrar, los ciudadanos polacos radicados en la ciudad de Buenos Aires fueron uno de los sectores más vulnerables ante las secuelas de la Gran Depresión. Dentro del conjunto de inmigrantes

90 Mirelman, 1988, 327-335.

91 Smolana, 1983, 56. 
de este origen, no todos los grupos étnicos fueron afectados de la misma forma y hubo una diferencia considerable en el impacto recibido entre polacos católicos y polacos judíos, diferencias que se deben a las particularidades de ambos movimientos migratorios, así como a un conjunto de factores interrelacionados entre sí.

La perdurabilidad de la crisis económica en Polonia, las fuertes tendencias proemigratorias del Estado polaco y las restricciones en la política inmigratoria estadounidense, convirtieron a la Argentina de entreguerras en uno de los principales países de destino. El crecimiento sostenido de los movimientos migratorios procedentes de tierras polacas registrado a mediados de la década de 1920, tuvo su auge, en el caso de los polacos católicos, en los años anteriores a la crisis económica mundial. En consecuencia, la primera época migratoria - que suele caracterizarse por un acceso reducido al mercado de trabajo y por un alto índice de inestabilidad laboral- coincidió, para un número elevado de inmigrantes polacos, con los primeros efectos de la caída de la actividad económica. Al agravarse la situación laboral y al desempeñar las tareas no calificadas, los polacos fueron unos de los primeros en sufrir reducciones de sueldo o convertirse en mano de obra prescindible.

A la situación laboral desfavorable se sumó, además, la incapacidad de la joven colectividad de afrontar las secuelas de la crisis. Las redes sociales existentes fueron incapaces de garantizar la contratación y, menos, la estabilización de los recién llegados. El creciente número de desocupados superó las escasas posibilidades de las estructuras étnicas polacas, carentes de socios y de fondos económicos. En consecuencia, su apoyo a los connacionales más necesitados fue mínimo. También fue escasa la ayuda económica del Estado polaco para sus ciudadanos en el exterior. Como resultado, la debilidad en los vínculos de paisanaje y la insuficiente capacidad asistencial de las instituciones étnicas obligó a los inmigrantes polacos a depender de mecanismos impersonales de contratación. El perfil profesional de los emigrados determinó, a su vez, la oferta laboral a la que podían acceder a través de este medio.

Como se ha señalado, se trataba mayoritariamente de obreros no calificados, peones o jornaleros, sin competencias técnicas suficientes para garantizar el acceso a un empleo estable. La mayoría no poseía el conocimiento del idioma castellano, lo que adicionalmente dificultaba su situación laboral. A estas características se sumaba el elevado índice de masculinidad, que respondía a los respectivos proyectos migratorios. Estos 
contemplaban el retorno al país de origen o preveían la reunificación familiar. Se trataba, pues, de individuos dispuestos a realizar cualquier trabajo, reducir al máximo el gasto y enviar sistemáticamente el dinero a Polonia. Seguidamente, la falta de ahorros imposibilitaba afrontar los cada vez más prolongados periodos de desocupación y les hacía muy propensos a formar parte de uno de los precarios asentamientos de desocupados. Consecuentemente, la mayor vulnerabilidad de los polacos, en comparación con otros colectivos de origen inmigrante en el contexto argentino, no se debía a un más alto porcentaje de desocupados dentro de la comunidad, sino a la incapacidad del grupo para amortiguar las secuelas de la crisis.

Este impacto, en cambio, fue mucho menor entre los polacos judíos. En este caso, los proyectos migratorios que involucraban a todo el grupo familiar y que raras veces contemplaban la posibilidad de retorno, estaban enfocados en el país de destino. La especialización en determinados sectores laborales contribuyó, por un lado, al reforzamiento de las cadenas migratorias y, por el otro, aseguró la movilidad social ascendente del grupo. Los vínculos de paisanaje, al parecer mucho más fuertes que entre sus connacionales católicos, crearon un eficaz sistema de ayuda y permitieron una mayor estabilidad laboral. La intensa participación de los inmigrantes judíos en las asociaciones voluntarias fundadas en la ciudad de Buenos Aires, aseguró la existencia de fuertes estructuras colectivas. Estas, además, se fueron retroalimentando con las de los judíos askenazíes de otras nacionalidades, lo que permitió establecer una poderosa red de instituciones asistenciales, capaz de atenuar, al menos parcialmente, las consecuencias de la crisis económica.

Recibido el 16 de febrero de 2017 Segunda versión el 15 de noviembre de 2017

Aceptado el 18 de diciembre de 2017

\section{Referencias bibliográficas}

Barbero, María Inés y Felder, Susana, «Los obreros italianos de la Pirelli argentina (1920-1930)», en Devoto, Fernando y Míguez, Eduardo (comps.), Asociacionismo, trabajo e identidad étnica, Buenos Aires, CEMLA, CSER, UNCPBA, 1992, 189-203.

Bargman, Daniel, «Judíos oriundos de Polonia en Argentina. Construcciones identitarias y asociacionismo étnico hasta la segunda posguerra», en Kahan, Emmanuel et al. (comps.), Marginados y consagrados. Nuevos estudios sobre la vida judía en la Argentina, Buenos Aires, Lumiere, 2011, 165-190. 
Brożek, Andrzej, «Polityka imigracyjna w państwach docelowych emigracji polskiej (1850-1939)», en Pilch, Andrzej (coord.), Emigracja z ziem polskich w czasach nowożytnych i wspótczesnych, Varsovia, Państwowe Wydawnictwo Naukowe, 1984, 141-195.

Cagiao Vila, Pilar, «La experiencia argentina de las mujeres gallegas», en Farias, Ruy (comp.), Buenos Aires Gallega. Inmigración, pasado y presente, Buenos Aires, Comisión para la Preservación del Patrimonio Histórico Cultural de la Ciudad Autónoma de Buenos Aires, 2007, 155-166.

Ceva, Mariela, Empresas, trabajo e inmigración en la Argentina. Los casos de la Fábrica Argentina de Alpargatas y la Algodonera Flandria (1887-1955), Buenos Aires, Biblos, 2010a.

Ceva, Mariela, «1930-1945: crisis mundial, industria y migraciones internas», en Ceva, Mariela; Jáuregui, Aníbal y Stortini, Julio (eds.), Manual de Historia Social Argentina. Tomo I (1852-1976), Buenos Aires, Prometeo Libros, 2010b, 89-108.

Devoto, Fernando, «La inmigración de ultramar», en Torrado, Susana (comp.), Población y bienestar en la Argentina del primero al segundo Centenario, Buenos Aires, Edhasa, 2007, tomo I, 531-548.

Devoto, Fernando, Historia de la inmigración en la Argentina, Buenos Aires, Editorial Sudamericana, 2009.

Gelman, Jorge y Barsky, Osvaldo, Historia del agro argentino: Desde la conquista hasta comienzos del siglo XXI, Buenos Aires, Sudamericana, 2009.

Girbal-Blacha, Noemí, «La Junta Nacional para Combatir la Desocupación. Tradición y modernización socioeconómica en los años 30», Revista Estudios del Trabajo, 25, 2003, 25-53.

González Leandri, Ricardo, «La nueva identidad de los sectores populares», en Cattaruzza, Alejandro (dir.), Nueva historia argentina. Crisis económica, avance del estado e incertidumbre política (1930-1943), VII, Buenos Aires, Sudamericana, 2001, 201-238.

Fernández, Alejandro, «El asociacionismo español en Argentina: una perspectiva de largo plazo», en Blanco Rodríguez, Juan Andrés (ed.), El asociacionismo en la emigración española a América, Salamanca, UNED Zamora / Junta de Castilla y León, 2008, 469-501.

Iñigo Carrera, Nicolás y Fernández, Fabián, «El movimiento obrero ante la organización y formas de rebelión de los desocupados: 1930-1935», CICLOS en la historia, la economía y la sociedad, 16, 31-32, Córdoba (Argentina), 2007, 125-152.

Janowska, Halina, «Emigracja z Polski w latach 1918-1939», en Pilch, Andrzej (ed.), Emigracja z ziem polskich w czasach nowożytnych i najnowszych (XVIII-XX w.), Varsovia, Państwowe Wydawnictwo Naukowe, 1984. 
Kalendarz-Informator Polonji Argentyńskiej, Buenos Aires, Kooperatywa Handlowo-Przemysłowa i Rolna Energja, 1931.

Klarner-Kosińska, Izabela, «Polonia w Buenos Aires», en Kula, Marcin (coord.), Dzieje Polonii w Ameryce Łacińskie: zbiór studiów, Wrocław, Zakład Narodowy im. Ossolińskich, 1983, 218-243.

Korol, Juan Carlos, «La economía», en Cattaruzza, Alejandro (dir.), Nueva Historia Argentina. Crisis económica, avance del Estado e incertidumbre política (1930-1943), VII, Buenos Aires, Sudamericana, 2001, 17-47.

Kowalska, Marta, «La emigración judía de Polonia a la Argentina en los años 19181939», Estudios Latinoamericanos, 12, Varsovia, 1989, 249-272.

Llavallol. Ojeando recuerdos, Buenos Aires, Comisión de Estudios Históricos de Llavallol, 1992.

Lobato, Mirta, La vida en las fábricas. Trabajo, protesta y política en una comunidad obrera, Berisso (1940-1970), Buenos Aires, Prometeo Libros, 2001.

Maty Rocznik Statystyczny 1939, Varsovia, Główny Urząd Statystyczny, 1939.

Matelski, Dariusz, «Polityka Drugiej Rzeczypospolitej wobec mniejszości narodowych, optantów, emigrantów, reemigrantów i cudzoziemców», en Adamczyk, Anita; Sakson, Andrzej y Trosiak, Cezary (coords.), Polityczne $i$ społeczne aspekty wielokulturowości. Migracje i mniejszości, Poznań, Uniwersytet im. Adama Mickiewicza w Poznaniu, 2016, 189-204.

Mazurek, Jerzy, Kraj a emigracja. Ruch ludowy wobec wychodźstwa chłopskiego do krajów Ameryki Łacińskiej (do 1939 roku), Varsovia, Instytut Studiów Iberyjskich i Iberoamerykańskich Uniwersytetu Warszawskiego i Muzeum Historii Polskiego Ruchu Ludowego w Warszawie, 2006.

Mazurek, Jerzy, «Polacy w Ameryce Łacińskiej: Piśmiennictwo polskie», en Stemplowski, Ryszard (coord.), Polacy, Rusini i Ukraińcy, Argentyńczycy. Osadnictwo w Misiones 1892-2009, Varsovia, Muzeum Historii Polskiego Ruchu Ludowego / Instytut Studiów Iberyjskich i Iberoamerykańskich UW, 2011, 39-58.

Mirelman, Víctor, En búsqueda de una identidad: los inmigrantes judíos en Buenos Aires 1890-1930, Buenos Aires, Ed. Milá, 1988.

Nalewajko, Małgorzata, «Los polacos hacia América Latina. La política emigratoria del gobierno polaco en el periodo de entre guerras», en González Martínez, Elda y Fernández, Alejandro (eds.), Migraciones internacionales, actores sociales y Estados: perspectivas del análisis histórico, Madrid, Iberoamericana Vervuert, 2014, 129-147.

Oteiza, Enrique, Inmigración y discriminación. Políticas y Discursos, Buenos Aires, Trama Editorial, 2000.

Palacio, Juan Manuel, «La antesala de lo peor: La economía argentina entre 1914 y 1930», en Falcón, Ricardo (dir.), Nueva Historia Argentina. Democracia, 
conflicto social y renovación de ideas (1916-1930), VI, Buenos Aires, Editorial Sudamericana, 2000, 101-150.

Panettieri, José, «Paro forzoso y colocación obrera en Argentina en el marco de la crisis mundial (1929-1934)», Cuadernos del CISH, 1, 1, 1996, 9-30.

Porada, Katarzyna, «La configuración de las políticas migratorias en el país de origen y en el de destino: la llegada de los europeos a Argentina», en González Martínez, Elda (comp.), Políticas y prácticas de protección a los emigrantes, Madrid, Polifemo, 2016.

Ré, Juan Alejandro, El problema de la mendicidad en Buenos Aires: sus causas y remedios, Buenos Aires, Talleres Gráficos, 1938.

Smolana, Krzysztof, «Za ocean po lepsze źycie», en Kula, Marcin (coord.), Dzieje Polonii w Ameryce Łacińskiej, Wrocław, Zakład Narodowy im. Ossolińskich, 1983, 39-60.

Smolana, Krzysztof, «Juntos a través de la historia. Boceto histórico de las relaciones polaco-argentinas», en Dembicz, Andrzej (coord.), Relaciones entre Polonia y Argentina: pasado y presente, Varsovia, Centro de Estudios Latinoamericanos, 1996, 40-56.

Snitcofsky, Valeria, «Impactos urbanos de la gran depresión: el caso de Villa Desocupación en la ciudad de Buenos Aires (1932-1935)», Cuaderno Urbano. Espacio, Cultura, Sociedad, 15, Corrientes (Argentina), 2013, 93-109.

Stemplowski, Ryszard (coord.), Polacy, Rusini i Ukraińcy, Argentyńczycy Osadnictwo w Misiones 1892-2009, Varsovia, Muzeum Historii Polskiego Ruchu Ludowego / Instytut Studiów Iberyjskich i Iberoamerykańskich UW, 2011.

Trybiarz, Fiszel, Villa Lynch en silencio. Inmigrantes judios de Bialystok, Belchatow y Lodz y la industria textil, Buenos Aires, Editorial Milá, 2006.

Trybus, Adam, «Życie i praca polskich robotników w Comodoro Rivadavia», Kalendarz 1935, Buenos Aires, 1935, 39-48.

Vera de Flachs, María Cristina y Manachino de Pérez Roldán, Isabel, «La colectividad polaca en una provincia argentina en el período de entreguerras, 1927-1930», en Malinowski, Mariusz y Miodunka, Władysław (coords.), Comunidades de ascendencia centro-oriental europea en América Latina al advenimiento del siglo XXI, Varsovia, CESLA, 2001, 183-204.

Włodek, Józef, Argentyna i emigracja ze szczególnym uwzględnieniem emigracji polskiej, Varsovia, Wydawnictwo M. Arcta w Warszawie, 1923. 